\title{
Süstalinable Chemistry\& Engineering \\ DNA Coatings from Byproducts: A Panacea for the Flame Retardancy of EVA, PP, ABS, PET, and PA6?
}

\author{
Jenny Alongi, ${ }^{* \dagger}$ Fabio Cuttica, and Federico Carosio
}

Dipartimento di Scienza Applicata e Tecnologia, Politecnico di Torino, Alessandria campus, Viale Teresa Michel 5, 15121, Alessandria, Italy

\section{Supporting Information}

ABSTRACT: One of the most important challenges for thermoplastic polymers is to find flame retardants (FRs) capable of efficiently protecting them. At the same time, these desired FRs should be environmentally sustainable, cheap, and suitable for most of the polymers employed on the industrial scale. Obviously, it is almost impossible to design such a universal FR to be used for polymers having different chemical structures. We have recently demonstrated the efficiency of a deoxyribose nucleic acid (DNA) coating as a FR solution for cellulose and ethylene-vinyl-acetate (EVA) copolymer. Pursuing this research, in the present study we investigate the FR effect of different DNA amounts on $3 \mathrm{~mm}$ EVA samples in order to optimize its cost/

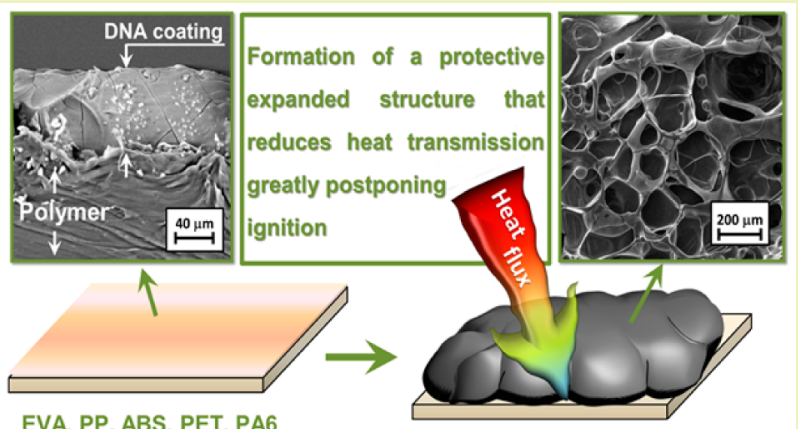
effectiveness ratio. FR performances were evaluated with a cone calorimeter under 35 and $50 \mathrm{~kW} / \mathrm{m}^{2}$. Then, the optimized DNA amount was tested on EVA samples having different thicknesses (namely, 1 and $6 \mathrm{~mm}$ ) in order to establish whether a correlation between DNA amount and sample mass exists. Finally, the DNA potentialities as "universal" FR have been investigated on samples of polypropylene (PP), acrylonitrile-butadiene-styrene (ABS), polyethyleneterephthalate (PET), and polyamide 6 (PA6) and compared with some of the best FR solutions found in the literature or on the market.

KEYWORDS: DNA, Coating, Combustion, Flame retardancy, Cone calorimeter

\section{INTRODUCTION}

Traditionally, one of the most common and easiest methods for conferring flame retardant properties to thermoplastic polymers is the addition of specific flame retardant chemicals during their processing. ${ }^{1}$ In numerous cases, the best performing systems are the so-called intumescent formulations (typically constituted of three components: a carbon source, an acid, and a blowing agent) that are able to protect the polymer by creating on its surface an expanded carbonaceous multilamellar structure (char) that hinders the heat, oxygen, and mass transfer from the atmosphere/flame during combustion. ${ }^{2-6}$ With this protective barrier, it is possible to achieve significant resistance to a flame or a radiating heat flux.

Subsequently, following the above mentioned results and FR action, a different concept based on surface protection has been developed and recently demonstrated as a worthy alternative to bulk inclusion. $^{7-9}$ This latter approach may exhibit some advantages with respect to the bulk one; indeed, in theory a coating can be deposited on all polymeric surfaces, taking into account the adhesion between the two materials (or promoting it if needed), without changing the polymer bulk properties that, on the other hand, often suffer from detrimental effects due to effect of additive inclusion (e.g., reduced mechanical properties, modified processing conditions).
In this scenario, seeking new eco-friendly FRs capable of meeting recent societal demands for the replacement of current toxic solutions, ${ }^{10}$ our group has investigated the use of DNA and its potentialities thanks to its intrinsically intumescent nature. ${ }^{11}$

Such a complex yet effective molecule turned out to be very efficient when used as a coating for cotton fibers ${ }^{12}$ and achieved unpredictable results in the case of an EVA copolymer (containing 18 wt $\%$ of vinyl acetate). ${ }^{13,14}$ For this latter material, DNA has been used either as flame retardant or functional coating exhibiting comparable results with ammonium polyphosphate when added in bulk and outperforming it (increase in time to ignition and peak of heat release rate reduction, as assessed by cone calorimetry) when deposited on EVA surface. Figure 1 reports the chemical structure of DNA with its relationship to a flame retardant intumescent system and a schematization of the DNA coating flame retardant action.

The phosphate groups produce phosphoric acid. The deoxyribose units represent the carbon source, and the nitrogen-containing bases (i.e., adenine, guanine, cytosine,

Received: March 28, 2016

Revised: $\quad$ May 16, 2016

Published: May 17, 2016 


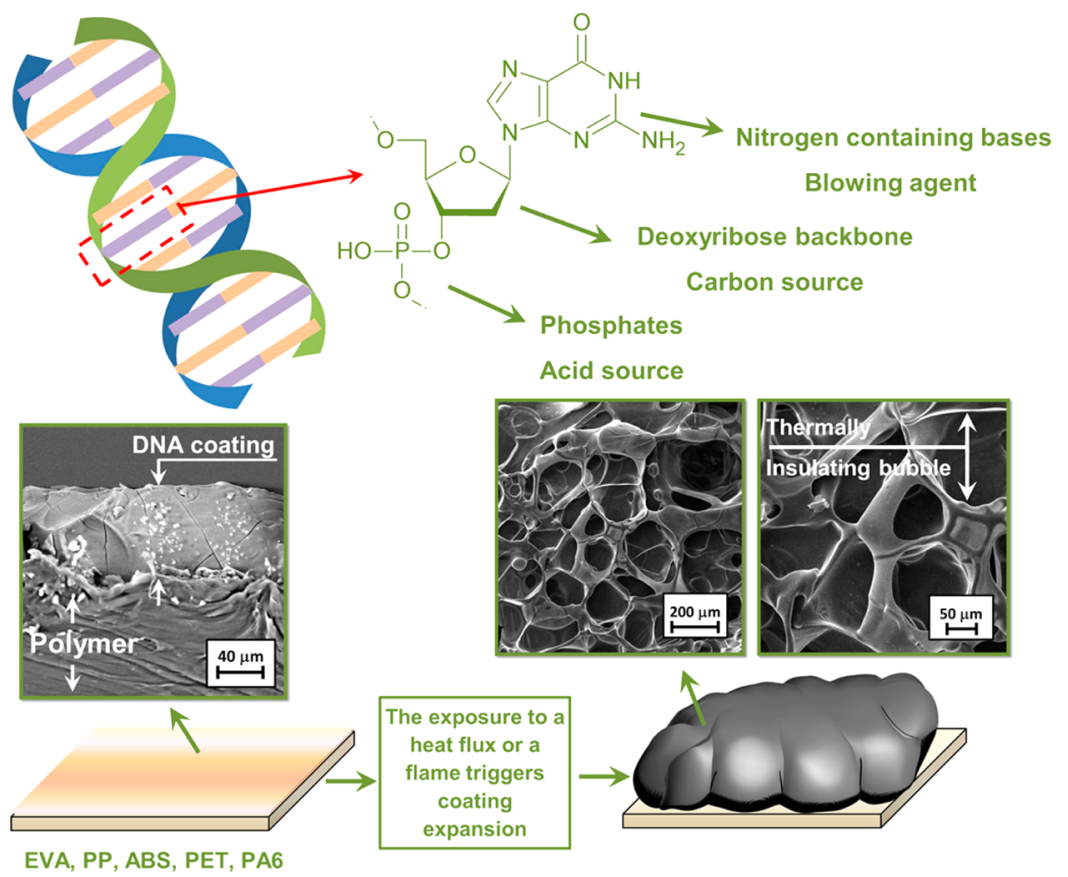

Figure 1. Chemical structure of a DNA segment and its relationship to an intumescent flame retardant system.

and thymine) act as blowing agents releasing ammonia. ${ }^{11}$ The following is the flame retardant mechanism of a DNA coating deposited on polymeric substrates: upon heating or flame exposure, the DNA swells (degree of expansion is 20 times the initial thickness) and produces a protective foamed structure with thermal shielding properties. After deposition on the surface, DNA coating (15 wt \% on its EVA) blocked the ignition of the copolymer when tested by a cone calorimeter under $35 \mathrm{~kW} / \mathrm{m}^{2}$ heat flux, increasing the time to ignition by ca. 200 s (i.e., $+380 \%$, with respect to untreated EVA), while it significantly postponed (about $100 \mathrm{~s},+625 \%$ with respect to untreated copolymer) and reduced the combustion kinetic rate under $50 \mathrm{~kW} / \mathrm{m}^{2}$ flux. In addition, the DNA coating was found to be able to protect the underlying EVA from the flame of a butane/propane torch preventing the polymer from melting, thus providing promising results from the reaction to flame application point of view. ${ }^{13}$

These preliminary results have on one hand opened a totally new scenario in terms of fire protection; while on the other hand, they left many unanswered scientific questions concerning the use of DNA-based coatings. Both aspects have encouraged the study presented here.

The DNA cost is higher than those of traditional commercial FRs, and although the large-scale preparation method developed by Wang and co-workers ${ }^{15}$ has enabled DNA to become competitive with other chemicals, it cannot compete with commercial FRs in terms of raw material costs. Thus, in our opinion, it is of both scientific and industrial interest to reduce the amount employed for the proposed treatments in order to guarantee a good cost/effectiveness ratio. To this, we compared the results already observed with those achieved by reducing the DNA:EVA weight content from 15 down to 5 and 10 wt $\%$. Subsequently, the same 5 and 10 wt \% add-ons have been transferred on EVA samples having different thicknesses (namely, 1 and $6 \mathrm{~mm}$ ).

The aim of the present work was to establish whether (i) a correlation, or better a threshold value, exists between DNA amount employed and polymer sample mass (thus thickness) and (ii) the DNA efficiency in protecting EVA depends only on the coating surface exposed to the radiating heat.

This point is crucial: indeed, if a certain amount of DNA is able not only to create a char (as depicted in Figure 1) suitable to reduce the transmitted heat flux in the cone calorimeter, thereby reducing the temperature detected by the polymer, but also hinder the heat, oxygen, and mass transfer from the atmosphere, the surrounded polymer will not reach its flammability limits and will undergo pyrolysis rather than combustion.

On the basis of such a hypothesis, this finding may mean that, if the coating can act independently from the chemical structure and degradation pathways of the coated polymer, it can be applied to all polymers, thus representing a general solution to polymer flammability. This achievement might be an industrial breakthrough as nowadays fire protecting solutions that rely on bulk inclusion are specifically designed as functions of the polymer being protected, more often requiring extremely high loading (30-50 wt \%) in order to achieve the FR desired properties. For instance, EVA formulations containing inorganic flame retardants can reach a loading as high as 6070 wt \%. ${ }^{16}$ It is thus evident how such a general solution could simplify and make more straightforward the protection of polymers.

In order to verify this hypothesis, we selected four polymers (that together represent $30 \%$ of worldwide polymer production), namely PP, ABS, PET, and PA6, and coated them with a DNA amount optimized during the first step of the present study (as schematically represented in Figure 1). The resulting combustion properties have been measured using a cone calorimeter in order to simulate the conditions of a real fire scenario. This test is widely adopted as a research and development tool as it provides useful information concerning the combustion behavior of a polymer when exposed to an incident heat flux (i.e., time to ignition, heat release rate, $\mathrm{CO}$ and $\mathrm{CO}_{2}$ production). Two testing conditions have been 
(a)

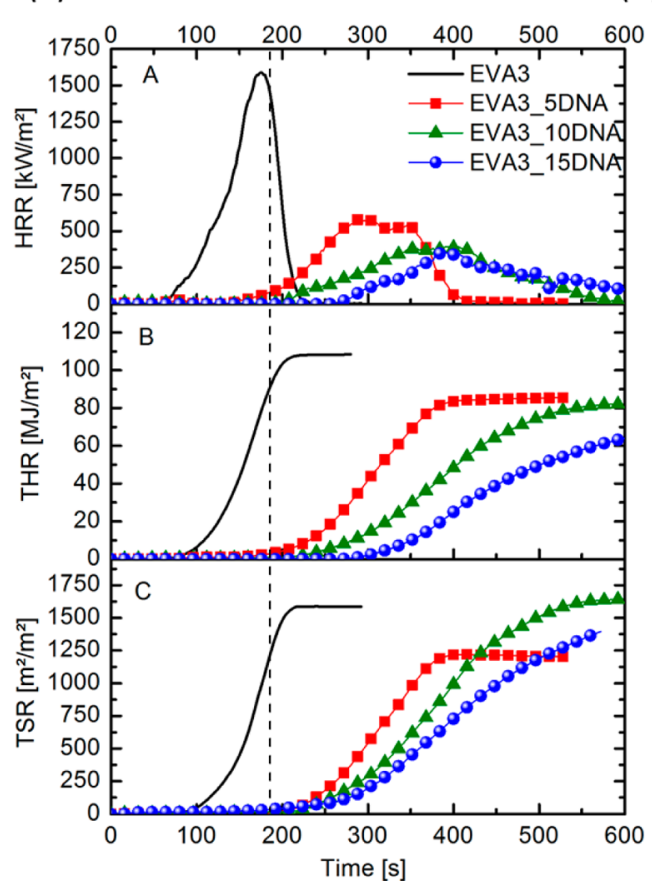

(b)

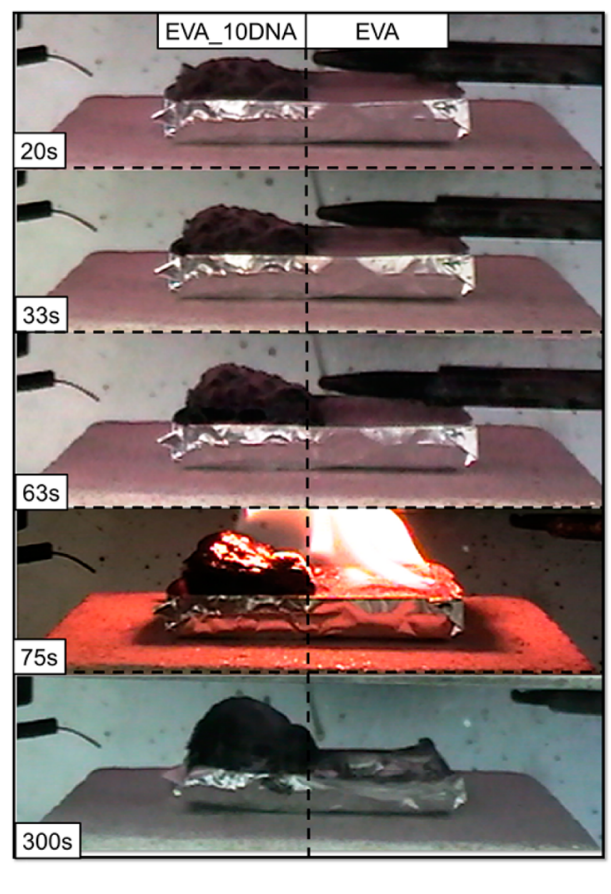

Figure 2. (a) Cone calorimetry data plots at $35 \mathrm{~kW} / \mathrm{m}^{2}$ for EVA and EVA treated with 5, 10, and 15 wt \% DNA: (A) heat release rate (HRR), (B) total heat release (THR), and (C) total smoke release (TSR). Dashed line marks the end of combustion for untreated EVA sample. (b) Snapshots taken at different times during the cone calorimetry test of an EVA sample with only $50 \%$ of the surface coated with DNA.

selected mimicking the heat fluxes normally found in developing fires (i.e., 35 and $50 \mathrm{~kW} / \mathrm{m}^{2}$ ). The higher irradiation levels correspond to more developed fires. ${ }^{17}$ Finally, the heat releasing performances of DNA-coated polymers have been compared with those of the most performing FR systems found in the literature.

\section{EXPERIMENTAL SECTION}

Materials. An EVA copolymer containing 18 wt \% vinyl acetate (Elvax470 from DuPontTM; MFI, $0.7 \mathrm{~g} / 10 \mathrm{~min}$ ), PP (HP500N from Basell Polyolefins S.r.l.; MFI, $12 \mathrm{~g} / 10 \mathrm{~min}$; density, $0.90 \mathrm{~g} / \mathrm{m}^{3}$ ), PA6 (Aquamid AQ27000 from Aquafil S.p.A; density, $1.14 \mathrm{~g} / \mathrm{m}^{3}$ ), ABS (Magnum3453 from Dow; MFI, $15 \mathrm{~g} / 10 \mathrm{~min}$; density, $1.050 \mathrm{~kg} / \mathrm{m}^{3}$ ) and PET (from Sinterama S.p.A.; MFI, $15 \mathrm{~g} / 10 \mathrm{~min}$ ) were used.

DNA from herring sperm was supplied as a high purity grade (98\%) reagent by Sigma-Aldrich, Inc. and used as received.

Deposition of DNA on Polymers. A total of 0.65 or $0.32 \mathrm{~g}$ of DNA was uniformly deposited on EVA square plates having $3 \mathrm{~mm}$ thickness $(6.5 \pm 0.5 \mathrm{~g})$ and subsequently compressed, using a hot compression molding press at $120^{\circ} \mathrm{C}$ for $1.5 \mathrm{~min}$ (applied pressure: 5 $\mathrm{MPa}$ ). This process yields a homogeneous coating that completely covers the surface of the specimen.

DNA content to EVA: 10 and 5 wt \%. The same procedure was employed for EVA samples having 1 or $6 \mathrm{~mm}$ thickness.

Hereafter, we will refer to such samples employing the following codes: EVAX_YDNA, which point out the sample thickness (namely, $\mathrm{X}$ ) and $\mathrm{DNA} /$ polymer weight percent composition (Y). As an example, EVA3_10DNA indicates an EVA sample having $3 \mathrm{~mm}$ thickness, covered by a DNA amount in order to have a DNA/EVA weight content equal to $10 \%$. Sample codes and formulations cited in the present work have been summarized in Table S1 in the Supporting Information.

The same procedure mentioned above was employed for PP, ABS, PET, and PA6 samples having $3 \mathrm{~mm}$ thickness and $10 \mathrm{wt} \%$ as DNA/ (co)polymer weight composition. In this case, the adopted codes were as follows: (CO)POLYMER_DNA, where (CO)POLYMER can be PP, ABS, PET, or PA6.
Characterization Techniques. Cone calorimeter tests (Fire Testing Technology) were performed according to the ISO 5660 standard. ${ }^{18}$ Then, $50 \times 50 t \mathrm{~mm}^{3}$ (where $t=1$, 3 , or $6 \mathrm{~mm}$ ) samples were placed on a sample holder and irradiated at a heat flux of 35 or 50 $\mathrm{kW} / \mathrm{m}^{2}$ in horizontal configuration. For each formulation, the test was repeated three times, and an experimental error of $5 \%$ was calculated for all of the measured parameters. Prior to combustion tests, samples were conditioned at $23 \pm 1{ }^{\circ} \mathrm{C}$ at $50 \%$ relative humidity for $48 \mathrm{~h}$.

Time to ignition (TTI, s), total heat release (THR, $\mathrm{MJ} / \mathrm{m}^{2}$ ), heat release rate peak (PHRR, $\left.\mathrm{kW} / \mathrm{m}^{2}\right)$, total smoke release (TSR, $\mathrm{m}^{2} / \mathrm{m}^{2}$ ), and carbon monoxide and dioxide yields ([CO] and $\left.\left[\mathrm{CO}_{2}\right], \mathrm{g} / \mathrm{s}\right)$ were evaluated. The fire performance index (FPI, $\mathrm{sm}^{2} / \mathrm{kW}$ ) was calculated as a TTI to PHRR ratio for untreated and DNA-treated materials. The evaluation of such a parameter is very important in order to establish the real effectiveness of the proposed treatment; indeed, as claimed by Schartel and co-workers, ${ }^{19}$ the higher the FPI, the better are the flame retardant performances.

\section{RESULTS AND DISCUSSION}

Effect of DNA Amount on EVA. The cone calorimeter is a useful instrument for simulating the burning behavior of a material exposed to heat fluxes typically found during developing fires. During the test, square samples are exposed to a radiant heating source, which is maintained at a constant heat flux selected as a function of the fire stage under consideration (the higher the heat flux, the more developed is the fire). The values 35 and $50 \mathrm{~kW} / \mathrm{m}^{2}$ are the most widely adopted heat fluxes when testing polymers. The exposure to such heat flux triggers the production of combustible volatile species from the sample. These volatiles are then ignited by a spark ignite, causing the flaming combustion of the samples. The heat release during combustion is then measured by the evaluation of the oxygen consumed during combustion $(13.1 \mathrm{~kJ}$ of heat are released per gram of oxygen consumed). Figure 2 reports cone calorimetry data plots and sample burning images 
at $35 \mathrm{~kW} / \mathrm{m}^{2}$ for EVA and EVA treated with different amounts of DNA.

Under a heat flux of $35 \mathrm{~kW} / \mathrm{m}^{2}$, all three DNA amounts employed for covering EVA samples having a $3 \mathrm{~mm}$ thickness are able to significantly postpone the copolymer ignition (TTI values increase from $66 \mathrm{~s}$ to 162,206 , and $276 \mathrm{~s}$ for EVA3_5DNA, EVA3_10DNA, and EVA15_DNA, respectively, and considerably reduced the PHRR by at least $70 \%$; Figure 2A). Furthermore, THR values are significantly reduced, while TSR is reduced only by $5 \%$, and it remains unchanged at higher add-ons (Figure 2B and C).

Comparing the HRR curves of untreated and DNA-treated samples, it is noteworthy that, due to the extremely high delay in ignition imparted by the DNA coating, the complete combustion of neat EVA takes place before those of DNAtreated samples start. Thus, during the time corresponding to combustion of untreated EVA, the heat and smoke released from the other samples, regardless of DNA amount, are close to zero (see THR and TSR plots in Figures 2a).

In order to make a visual proof of the fire protecting action of the DNA coatings, a sample coated only on $50 \%$ of its surface has been prepared, and its behavior during cone calorimetry tests is represented by the sequence of snapshots reported in Figure $2 b$.

After 20s of exposure, the coating starts to react, forming a carbonaceous structure that tends to blow up; at longer and longer times, the expansion of such a structure goes on, and the surrounded polymer starts to pyrolyse and does not ignite. On the contrary, upon heating, neat EVA immediately starts to decompose and after about $60 \mathrm{~s}$ ignites, undergoing a flaming combustion that completely consumes the sample. By monitoring combustion as carbon monoxide and dioxide yields (Figure 3), it is possible to observe a drastic decrease of these

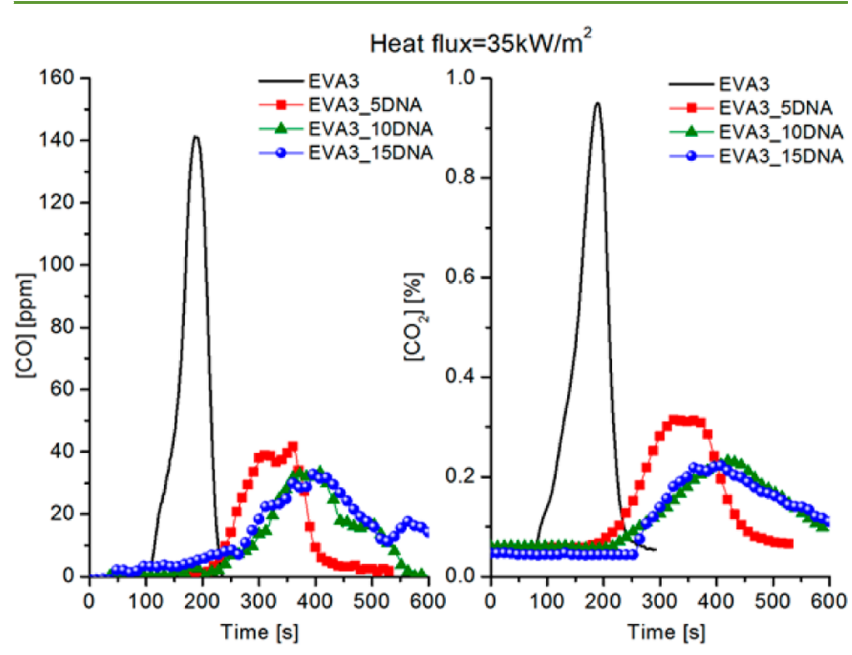

Figure 3. $\mathrm{CO}$ and $\mathrm{CO}_{2}$ production during cone calorimetry tests for EVA and EVA treated with 5, 10, and 15 wt \% DNA.

two parameters in the presence of DNA that, by favoring the char formation from EVA, reduces the release of volatile species, thereby inhibiting combustion.

By comparing the behavior of 5, 10, and 15 wt \% DNA, it is clear that there is a direct dependence between the DNA amount and the obtained performances: the lower the DNA add-on, the lower are the resulting fire performances. On the other hand, even the lowest performance achieved with 5 wt \% DNA can be considered very relevant if compared with other
EVA bulk systems employing an FR loading of 30-35 wt $\% .^{20,21}$ Furthermore, these results show also that it is possible to reduce the DNA add-on with respect to that used in our previous study, ${ }^{12}$ maintaining high performance in terms of the large increases in TTI observed.

We can conclude that 10 wt \% DNA is the optimized amount that can guarantee a good probable cost/effectiveness ratio of the proposed treatment. Combustion tests by cone calorimetry have been repeated, under a higher heat flux, namely $50 \mathrm{~kW} /$ $\mathrm{m}^{2}$, on EVA3 and EVA3 coated with 10 and 15 wt \% DNA (Figure $\mathrm{S} 1$ reported in the Supporting Information). Once again, the DNA presence is fundamental in order to increase EVA TTI and reduce its PHRR value (Figure S1aA) and THR (Figure $\mathrm{S} 1 \mathrm{aB}$ ). As expected, by increasing the heat flux, the combustion duration is reduced; thus, the coating efficiency is more important as it must react more rapidly in blocking EVA decomposition. The curves reported in Figure S1 (a) demonstrate that the efficiency of DNA is very high also in these drastic conditions of radiating heat.

Comparing the performances of EVA3_10DNA and EVA3_15DNA, it is clear that the highest protection level is achieved with the highest DNA add-on, but in both cases the protection level is very high in terms of increasing TTI and reducing PHRR values. As a matter of fact, $10 \mathrm{wt} \%$ DNA can be considered already sufficiently able to protect EVA, significantly postponing its ignition and reducing the other combustion parameters. Thus, as our aim was to achieve the highest cost/effectiveness ratio, the further development of the present research has been focused on using $10 \mathrm{wt} \%$ as the maximum content of DNA on the polymer surface.

Effect of Sample Thickness. Following the above results, 5 and $10 \mathrm{wt} \%$ of DNA have been applied on the surface of EVA samples having thicknesses of 1 and $6 \mathrm{~mm}$ in order to establish whether a correlation between the employed DNA amount and sample mass exists or not. A possibility, however, is that DNA efficiency depends only on the coating surface exposed to the radiating heat. Figure 4 reports the HRR curves obtained by cone calorimetry under $35 \mathrm{~kW} / \mathrm{m}^{2}$ heat flux.

Both 5 and $10 \mathrm{wt} \%$ turned out to be almost the same in efficiency for protecting EVA1, increasing the TTI (from 18 to about $50 \mathrm{~s}$ ) and reducing PHRR (by -27 and $36 \%$, respectively); overall, there are no significant differences between the performances of the two samples.

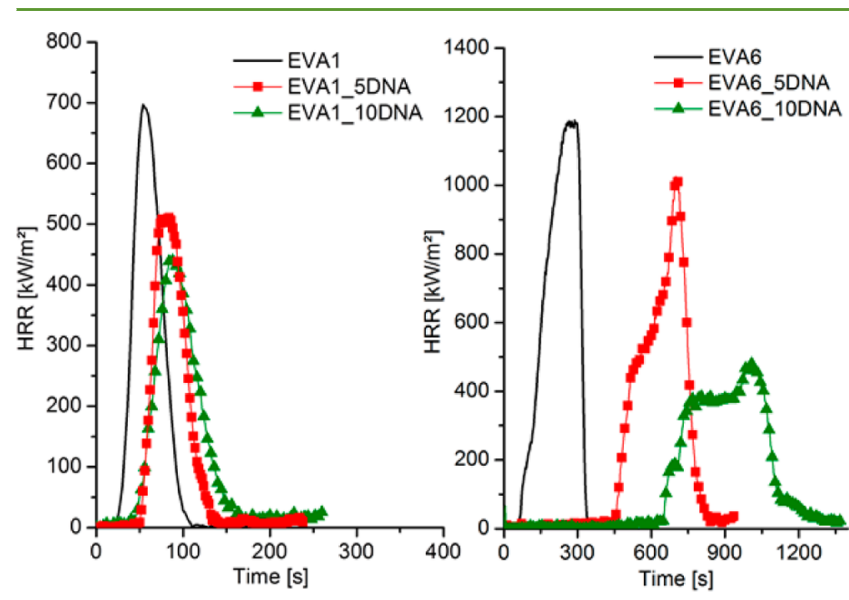

Figure 4. Heat release rate plots for uncoated and DNA-coated EVA samples having thicknesses of 1 and $6 \mathrm{~mm}$. 

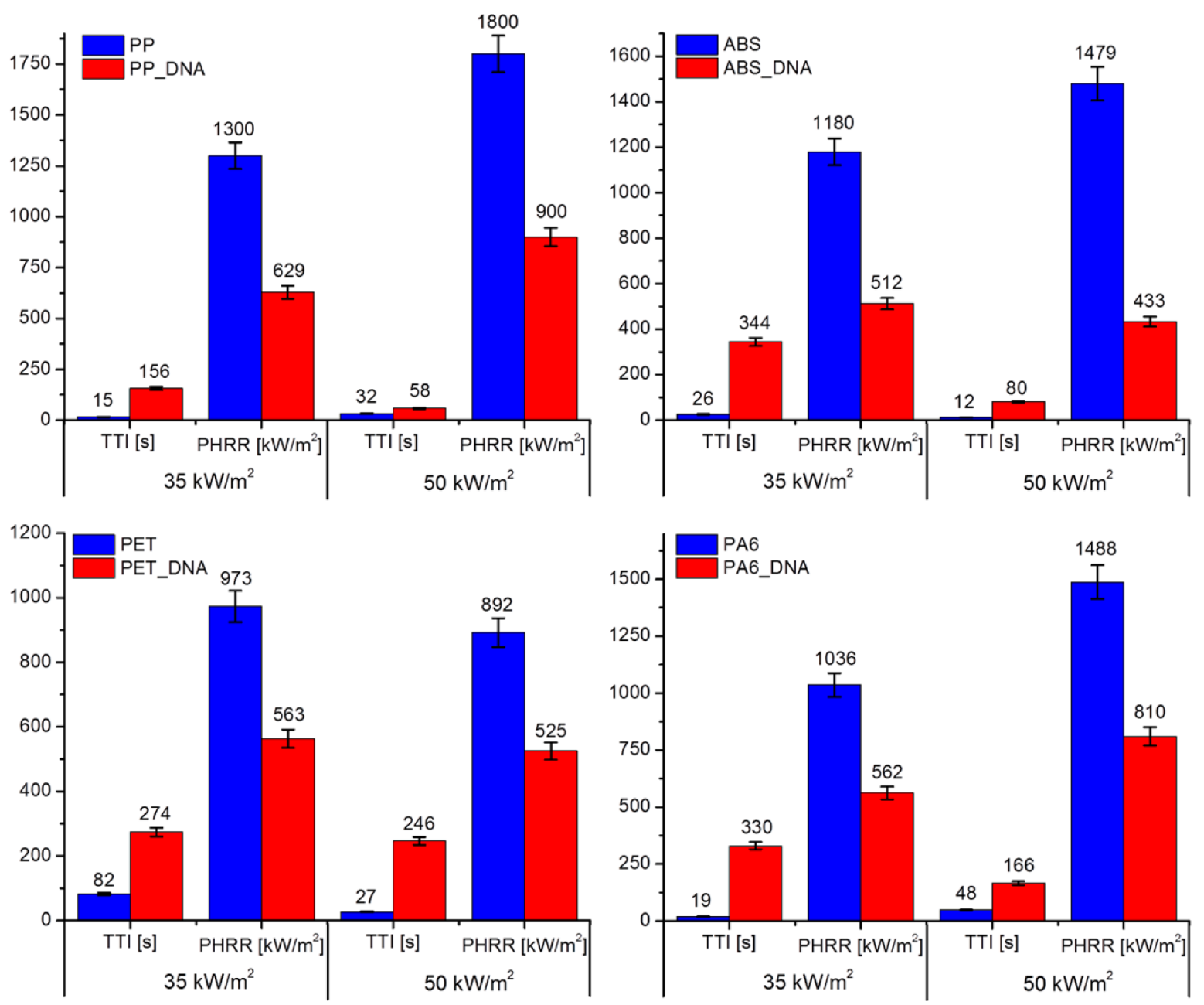

Figure 5. Histograms representing time to ignition (TTI) and peak of heat release rate (PHRR) for neat and DNA-coated PP (A), ABS (B), PET (C), and PA6 (D). Data collected during cone calorimetry test under 35 and $50 \mathrm{~kW} / \mathrm{m}^{2}$.

On the contrary, the two add-ons behaved differently when deposited on EVA samples with $6 \mathrm{~mm}$ thickness showing performances highly depending on the amount of coating addon. More specifically, with $5 \mathrm{wt} \%$, EVA TTI increases from 66 to $454 \mathrm{~s}$, but its PHRR is only slightly reduced (1024 vs. 1186 $\mathrm{kW} / \mathrm{m}^{2}$ for EVA6 5DNA and EVA6, respectively). On the other hand, with $\overline{10} \mathrm{wt} \%$, TTI is increased up to $644 \mathrm{~s}$ and PHRR significantly reduced down to $477 \mathrm{~kW} / \mathrm{m}^{2}$ (-60\% with respect to the value of untreated EVA). It is worth mentioning that, in both cases, by the time the untreated EVA ends its combustion, all samples treated with DNA have not yet ignited. Indeed, as mentioned above, their ignition takes place at very long TTI and is followed by combustion characterized by low heat release kinetics (see HRR plots in Figure 4).

Comparing the three samples having three different thicknesses, 1, 3, and $6 \mathrm{~mm}$ (Figure S2A in the Supporting Information), it is possible to observe that the effect of $10 \mathrm{wt} \%$ DNA is different for each of them. In general, it induces an increase of EVA TTI and a decrease of its PHRR; more specifically, the effect of DNA amount appears to linearly depend on EVA thickness (and mass) in terms of TTI, but not for its PHRR. It is reasonable that by having more DNA on the surface of EVA6_10DNA, the expanding protective layer will be thicker and more efficient in protecting the underlying polymer, thus requiring more time to reach EVA ignition, in comparison with the other two samples. Furthermore, the sample thickness should also be taken into account. Indeed, 1 $\mathrm{mm}$ specimen behavior can be referred to as thermally thin, meaning that, during the test, the thermal gradient across the sample thickness will be close to zero. For this reason, the degradation of EVA and DNA expansion would start at similar times, thus minimizing the effect of an expanding intumescent layer. On the other hand, a 6-mm-thick sample would behave as a thermally thick material with a greater thermal gradient across the thickness. This likely affords the surface DNA layer the observed more efficient increase in TTI.

As far as the PHRR trend is concerned, Figure S2 shows that, by increasing DNA add-on, EVA PHRR linearly decreases only for samples having 1 and $3 \mathrm{~mm}$ thickness, but not for EVA6_10DNA ( $-36,-75$ and $-60 \%$, respectively). This trend can be explained observing the corresponding curves reported in Figures $2 \mathrm{a}$ and $4 \mathrm{~A}$ and $\mathrm{B}$. The curve of EVA1 10DNA is sharp and narrow. That of EVA3 10DNA is broad with a small maximum that cannot be considered a true peak, and that of EVA6 10DNA shows a broad distribution tending to a plateau with two maximum peaks at 400 and $477 \mathrm{~kW} / \mathrm{m}^{2}$. This latter trend suggests that during combustion after ca. $750 \mathrm{~s}$, a char is formed which is thermally stable up to $1100 \mathrm{~s}$, but afterward it is likely to be broken down. The cracks formed can allow the leak of combustible volatile species that then provoke a second slight increase of EVA PHRR (namely, the peak at $477 \mathrm{~kW} /$ $\mathrm{m}^{2}$ ). 


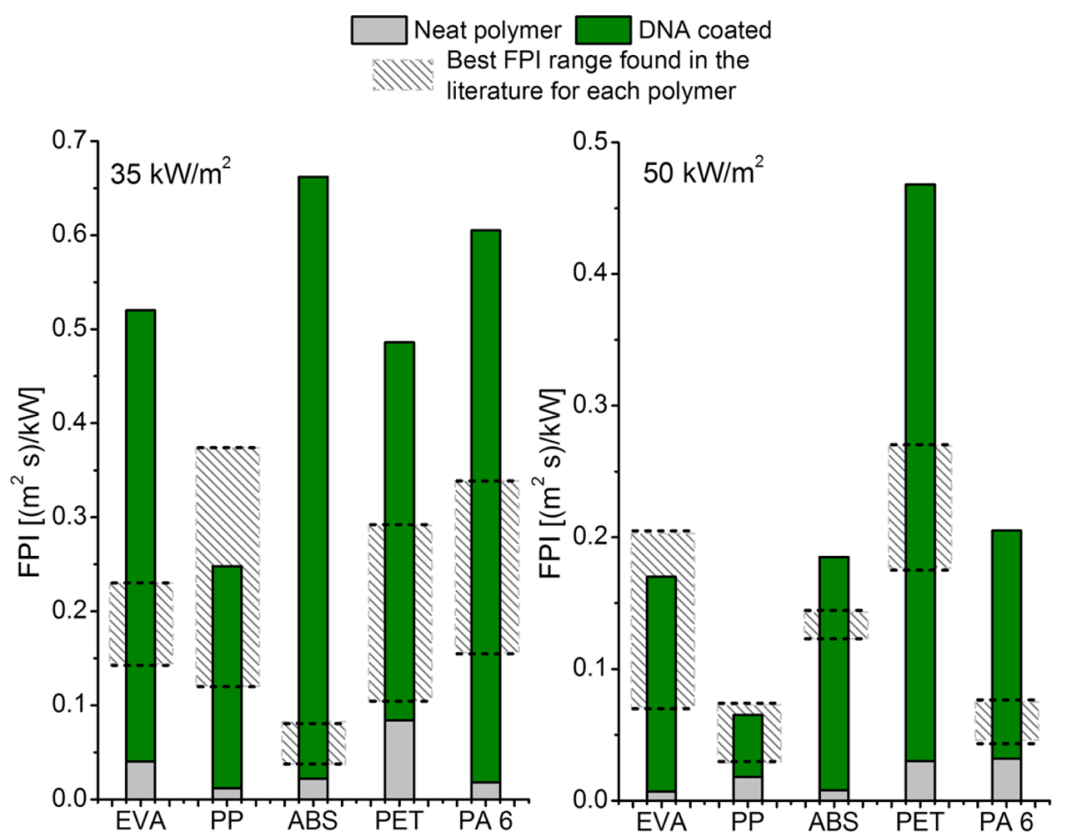

Figure 6. Histograms representing the FPI, calculated from cone calorimetry tests performed under 35 and $50 \mathrm{~kW} / \mathrm{m}^{2}$, of neat and DNA-coated polymers studied in the present paper. The area between dotted lines represents the range of the best FPI values achievable employing the literature data or commercial solutions for each polymer matrix.

In order to determine for each sample the contribution due to DNA presence on both TTI and PHRR, the FPI has been calculated and its trend reported in Figure S2B. As mentioned already in the Experimental Section, the FPI represents a fire safety engineering parameter often adopted in order to rate materials, at a quick glance, on the basis of their performances under the cone calorimetry: the higher the value, the better are the flame retardant performances according to the literature. ${ }^{19}$

It is evident that, for the same DNA amount, the higher the EVA thickness (and thus mass), the higher is the EVA FPI. Thus, we can conclude that in the proposed treatment, the DNA performances linearly depend on the polymer mass to be protected; this is also confirmed by the linear regression plotted in Figure S2C that well fits the DNA coated FPIs vs sample thickness data.

Extension of DNA Coatings to Other Polymers. As already mentioned in the Introduction, a further aim of the present work is to investigate the DNA performances on other polymer types, namely PP, ABS, PET, and PA6. On the basis of the results collected for EVA, we decided to test samples having $3 \mathrm{~mm}$ thickness and treated with $10 \mathrm{wt} \%$ DNA. Tests were performed on uncoated and DNA-coated samples under 35 and $50 \mathrm{~kW} / \mathrm{m}^{2}$ heat fluxes. Figure 5 reports the measured TTI and PHRR data for PP, ABS, PET, and PA6, presented together, for clarity reasons.

In general, regardless of the radiating heat adopted during the tests, DNA is observed to be very efficient in protecting all systems. The behavior is the same as already observed for EVA: TTI is increased and PHRR reduced in a significant way (see also Table S2 in the Supporting Information).

More specifically, as reported in Figure 5A for PP, PHRR reduction is approximately 50\%, regardless of the heat flux adopted. Quite surprising is very strong DNA effect on PP TTI, in particular when exposed to $35 \mathrm{~kW} / \mathrm{m}^{2}$ (from 15 to $156 \mathrm{~s}$, + $940 \%$ ). Indeed, when heated by the cone heat flux, the PP ignites after a very short TTI and vigorously burns, achieving the highest PHHR $\left(1300 \mathrm{~kW} / \mathrm{m}^{2}\right)$ among all tested polymers.
Thus, it can be considered that the substrate is more difficult to protect.

Referring to ABS (Figure 5B), TTI increases (+1223 and $567 \%$ for 35 and $50 \mathrm{~kW} / \mathrm{m}^{2}$, respectively) and PHRR reductions (-56 and $71 \%$ ) are even more relevant in comparison with the results achieved for PP under both fire conditions.

Comparing the behavior of PET and PA6 (Figures 5C and D), the PHRR reductions are almost the same, about $-45 \%$ (Figure 5 and Table S2). On the other hand, the DNA effect is different on TTI in relation to the adopted heat flux. Under 35 $\mathrm{kW} / \mathrm{m}^{2}$, the highest TTI increase has been achieved for PA6 $(+1637 \%)$, while under $50 \mathrm{~kW} / \mathrm{m}^{2}$, it is PET that yielded the highest increase $(+811 \%)$.

In order to highlight the real potential of the FR properties that could be achieved with a DNA coating, it is worth it to compare the data shown in the present paper with other flame retardant data found in the literature. In order to do this, the FPI values of DNA-coated polymers have been calculated and compared with those of the most efficient FR systems employing novel intumescent formulations, ${ }^{2}$ clay nanoparticles, $^{22}$ and commercially available FR solutions. ${ }^{23}$ Collected FPI values are reported in Figure 6 for each polymer matrix as histograms which report the calculated FPI values of neat and DNA-coated analogous polymers, while the area between dotted lines represents the range of the best FPI values achievable employing the different FR solutions mentioned above.

In all cases, DNA-treated materials exhibited FPI values much higher than those of their untreated analogues, often by 2 or 3 orders of magnitude, and in most cases the performances achieved with DNA coatings outperform other flame retardant systems as demonstrated by DNA-coated FPIs that are well above the indicated ranges in Figure 6. Only in the case of PP at both heat fluxes and EVA only at $50 \mathrm{~kW} / \mathrm{m}^{2}$, the FPI of the DNA-coated polymers falls within the calculated range of literature values. The above achievements basically show that 
the FR solution in terms of the FPI parameter proposed in the present manuscript can be considered the best performing one for ABS, PET, and PA6 and almost at the same level of other effective flame retardants for PP and EVA. Hence, the approach described by our research allows for a more possible environmentally sustainable route toward the safe and efficient fire protection of polymers.

\section{CONCLUSIONS}

In the present work, DNA has been used as a flame retardant coating for different polymeric substrates. The fire retardancy properties have been evaluated by means of cone calorimetry tests employing heat fluxes of 35 and $50 \mathrm{~kW} / \mathrm{m}^{2}$. During a first step, it has been demonstrated that 10 wt \% is the best DNA/ (co)polymer percent weight for guaranteeing a possible resource-effective optimum. Furthermore, our results have shown that DNA efficiency is not only linked to its presence on the surface but also to its amount. Indeed, 5\% DNA had good performances when deposited on 3-mm-thick EVA but almost completely lost such performances when the thickness was increased to $6 \mathrm{~mm}$.

Finally, and most importantly, the described DNA coating has been shown to be a potentially universal flame retardant for EVA, PP, ABS, PET, and PA6 outperforming or matching (in the case of PP and EVA) the fire performances (defined in terms of TTI, PHRR and FPI parameters) of currently available, effective FR solutions such as novel intumescent systems, nanocomposites, or commercial formulations. These results show that, in terms of cone calorimetric performances, the DNA molecule has great potential as a flame retardant protective coating. Its application can be implemented with UV-curing or other chemical cross-linking strategies in order to ensure the coating durability. In addition, if an industrial application is foreseen, further efforts are required in the near future in order to increase DNA availability by either investigating other sources (e.g., plants and fungi) or using DNA as a blueprint for the synthesis of new halogen-free flame retardant molecules.

\section{ASSOCIATED CONTENT}

\section{S Supporting Information}

The Supporting Information is available free of charge on the ACS Publications website at DOI: 10.1021/acssuschemeng.6b00625.

Sample codes with corresponding DNA add-on; cone calorimetry data plots at $50 \mathrm{~kW} / \mathrm{m}^{2}$ for EVA and EVA treated with 5, 10, and 15 wt \% DNA and snapshots taken at different times during the cone calorimetry tests; histograms from cone calorimetry tests for uncoated and DNA-coated EVA having thicknesses of 1,3 , and $6 \mathrm{~mm}$; and cone calorimetry data $\left(35\right.$ and $\left.50 \mathrm{~kW} / \mathrm{m}^{2}\right)$ of $\mathrm{PP}$, $\mathrm{ABS}, \mathrm{PET}$, and PA6 treated with DNA (PDF)

\section{AUTHOR INFORMATION}

\section{Corresponding Author}

*Tel./Fax: +39 0250314108. E-mail: jenny.alongi@unimi.it.

\section{Present Address}

${ }^{\dagger}$ Dipartimento di Chimica, Università degli Studi di Milano, Via Golgi 19, 20133 Milano, Italy

\section{Notes}

The authors declare no competing financial interest.

\section{ACKNOWLEDGMENTS}

The authors would like to thank Professor Giovanni Camino and Mr. Alessandro Di Blasio for the fruitful discussions.

\section{REFERENCES}

(1) Wilkie, C. A.; Morgan, A. B. Fire Retardancy of Polymer Materials, 2nd ed.; CRC Press: Boca Raton, FL, 2010.

(2) Alongi, J.; Han, Z.; Bourbigot, S. Intumescence: tradition versus novelty. A comprehensive review. Prog. Polym. Sci. 2015, 51, 28-73.

(3) Bourbigot, S.; Duquesne, S. Intumescent-based Fire Retardants. In Fire Retardancy of Polymeric Materials; Wilkie, C. A., Morgan, A. B., Eds.; CRC Press: Boca Raton, FL, 2010.

(4) Bourbigot, S.; Le Bras, M.; Duquesne, S.; Rochery, M. Recent advances for intumescent polymers. Macromol. Mater. Eng. 2004, 289 (6), 499-511.

(5) Camino, G.; Lomakin, L. S. Intumescent materials. In Fire Retardant Materials; Horrocks, R. A., Price, D., Eds.; Woodhead Publishing Ltd: Cambridge, UK, 2001.

(6) Camino, G.; Delobel, R. Intumescence. In Flame Retardancy of Polymers; Grand, A. F.; Wilkie, C. A., Eds.; M. Dekker Inc: New York, 2000.

(7) Malucelli, G.; Carosio, F.; Alongi, J.; Fina, A.; Frache, A.; Camino, G. Materials engineering for surface-confined flame retardancy. Mater. Sci. Eng., $R$ 2014, 84, 1-20.

(8) Liang, S.; Neisius, N. M.; Gaan, S. Recent developments in flame retardant polymeric coatings. Prog. Org. Coat. 2013, 76 (11), 1642-65.

(9) Weil, E. D. Fire-protective and flame-retardant coatings - A stateof-the-art. Review. J. Fire Sci. 2011, 29 (3), 259-96.

(10) Kemmlein, S.; Herzke, D.; Law, R. J. Brominated flame retardants in the European chemicals policy of REACH-Regulation and determination in materials. J. Chromatogr. A 2009, 1216 (3), 320333.

(11) Alongi, J.; Di Blasio, A.; Milnes, J.; Malucelli, G.; Bourbigot, S.; Camino, G. Thermal degradation of DNA, an all-in-one natural intumescent flame retardant. Polym. Degrad. Stab. 2015, 113, 110-118.

(12) Malucelli, G.; Bosco, F.; Alongi, J.; Carosio, F.; Di Blasio, A.; Mollea, C.; Cuttica, F.; Casale, A. Biomacromolecules as novel green flame retardant systems for textiles: an overview. RSC Adv. 2014, 4 (86), 46024-46039.

(13) Alongi, J.; Di Blasio, A.; Cuttica, F.; Carosio, F.; Malucelli, G. Bulk or surface treatments of ethylene vinyl acetate copolymers with DNA: investigation on the flame retardant properties. Eur. Polym. J. 2014, 51 (1), 112-119.

(14) Alongi, J.; Di Blasio, A.; Cuttica, F.; Carosio, F.; Malucelli, G. Flame retardant properties of ethylene vinyl acetate copolymers meltcompounded with deoxyribonucleic acid in the presence of $\alpha$-cellulose or $\beta$-cyclodextrins. Curr. Org. Chem. 2014, 18 (12), 1651-1660.

(15) Wang, L.; Yoshida, J.; Ogata, N. Self-assembled supramolecular films derived from marine deoxyribonucleic acid (DNA)-cationic surfactant complexes: large-scale preparation and optical and thermal properties. Chem. Mater. 2001, 13 (4), 1273-1281.

(16) Girardin, B.; Fontaine, G.; Duquesne, S.; Försth, M.; Bourbigot, S. Characterization of Thermo-Physical Properties of EVA/ATH: Application to Gasification Experiments and Pyrolysis Modeling. Materials 2015, 8, 7837-7863.

(17) Schartel, B.; Hull, T. R. Development of fire-retarded materials interpretation of cone calorimeter data. Fire Mater. 2007, 31 (5), 327354.

(18) Fire Test, Reaction to Fire - Part 1: Rate of Heat Release (Cone Calorimeter Method) + Part 2: Smoke Production Rate (Dynamic Measurement) + Part 3: Guidance on Measurement 2002 and 2003; ISO 5660; International Organization for Standardization: Geneva, Switzerland.

(19) Schartel, B.; Bartholmai, M.; Knoll, U. Some comments on the main fire retardancy mechanisms in polymer nanocomposites. Polym. Adv. Technol. 2006, 17 (9-10), 772-776.

(20) Lujan-Acosta, R.; Sánchez-Valdes, S.; Ramírez-Vargas, E.; Ramos-DeValle, L. F.; Espinoza-Martinez, A. B.; Rodriguez- 
Fernandez, O. S.; Lozano-Ramirez, T.; Lafleur, P. G. Effect of Amino alcohol functionalized polyethylene as compatibilizer for LDPE/EVA/ clay/flame-retardant nanocomposites. Mater. Chem. Phys. 2014, 146, 437-445.

(21) Wu, C.; Wu, W.; Qu, H.; Xu, J. Synthesis of a novel phosphazene derivative and it sapplication in intumescent flame retardant-EVA copolymer composites. Mater. Lett. 2015, 160, 282285.

(22) Kiliaris, P.; Papaspyrides, C. D. Polymer/layered silicate (clay) nanocomposites: An overview of flame retardancy. Prog. Polym. Sci. 2010, 35 (7), 902-958.

(23) Morgan, A. B.; Bundy, M. Cone calorimeter analysis of UL-94 V-rated plastics. Fire Mater. 2007, 31 (4), 257-283. 